\title{
Dynamic T-wave Changes with Hump Appearance from a Higher Intercostal Space in a Short QT Syndrome
}

Serhat Koca, Ozcan Ozeke, Serkan Cay, Firat Ozcan, Fazil Arisoy, Omer Alyan, Serkan Topaloglu and Dursun Aras

Türkiye Yüksek îhtisas Training and Research Hospital, Department of Cardiology, Ankara, Turkey

S hort QT syndrome (SQTS) is an inherited channelopathy associated with marked shortened QT intervals and sudden cardiac death. It is imperative for physicians to recognise the clinical features of the SQTS in making a timely correct diagnosis; however, the diagnosis of SQTS is further complicated by the presence of an overlapping range of QT intervals between affected cases and apparently healthy subjects. We present a case of SQTS with dynamic T-wave changes and T-wave hump appearance in the higher intercostal recordings, and speculate that these dynamic changes are a surrogate marker of underlying repolarisation abnormality and may help in the diagnosis of SQTS.

\section{Keywords}

Short QT syndrome, T-wave hump, electrocardiogram, intercostal space

Disclosure: Serhat Koca, Ozcan Ozeke, Serkan Cay, Firat Ozcan, Fazil Arisoy, Omer Alyan, Serkan Topaloglu and Dursun Arashave have no conflicts of interest to declare. No funding was received in the publication of this article.

Compliance with Ethics: All procedures were followed in accordance with the responsible committee on human experimentation and with the Helsinki Declaration of 1975 and subsequent revisions, and informed consent was received from the patient involved in this case study.

Authorship: All named authors meet the International Committee of Medical Journal Editors (ICMJE) criteria for authorship of this manuscript, take responsibility for the integrity of the work as a whole, and have given final approval to the version to be published.

open Access: This article is published under the Creative Commons Attribution Noncommercial License, which permits any non-commercial use, distribution, adaptation and reproduction provided the original author(s) and source are given appropriate credit.

Received: 11 February 2017

Accepted: 1 March 2017

Citation: European Journal of Arrhythmia \&

Electrophysiology, 2017;3(1):21-2

Corresponding Author: Ozcan Ozeke, Türkiye Yüksek îhtisas Hastanesi, Kardiyoloji Klinigi, Ankara, 06100, Turkiye. E: ozcanozeke@gmail.com
Short QT syndrome (SQTS) is a cardiac channelopathy characterised by an abnormally short QT interval and an increased risk of atrial and ventricular fibrillation. ${ }^{1}$ As it often involves young patients with an apparently normal heart, it is imperative for physicians to recognise the clinical features of the SQTS in making a timely correct diagnosis. The diagnosis of SQTS is further complicated by the presence of an overlapping range of QT intervals between affected cases and apparently healthy subjects. ${ }^{2}$ The dynamic wave abnormalities may be an important clue for this distinction.

\section{Case report}

A 28-year-old man was admitted after aborted sudden cardiac death with an electrical storm with four successive episodes of ventricular fibrillation. corrected QT (QTc) was $312 \mathrm{msec}$, suggesting SQTS (see Figure 1). His family history showed that an elder brother died suddenly at age 22, and his two brothers both were asymptomatic with short QT on their electrocardiograms (ECGS). The ECG taken from a higher intercostal space revealed dynamic T-wave changes in the precordial leads (see Figure 2, arrows) with a 'T-wave hump' appearance in V2 (see Figure 2B, arrow). Transthoracic echocardiography showed no structural abnormalities. An implantable cardiac defibrillator was implanted, and the patient was discharged with oral quinidine therapy without any complications, including T-wave oversensing.

\section{Discussion}

Electrocardiography is the primary important step in the diagnosis of SQTS but ECG findings may be easily ignored. Timely diagnosis and optimal treatment can significantly improve the overall prognosis of the patient and family members with SQTS. ${ }^{3}$ The main diagnostic criterion is a short QT interval seen in the baseline ECG, with QTC intervals $\leq 330 \mathrm{~ms}$ or QTC $<360 \mathrm{msec}$ with one or more of the following: a pathogenic mutation, family history of SQTS, family history of sudden death at age $\leq 40$ and/or survival of a ventricular tachycardia/ventricular fibrillation (VT/VF) episode in the absence of heart disease. ${ }^{3}$ On the other hand, using the QT interval corrected by Bazett's formula in the proposed diagnostic criteria has important limitations. ${ }^{4}$ As already observed in the first reported patient diagnosed. with SQTS, the QT interval in SQTS changes very little with changes in heart rate, and correction of the QT interval is therefore barely necessary at normal heart rates. ${ }^{5}$

In addition to the QT interval, other distinctive features associated with the ECGS of SQTS patients have been reported, including the relative absence of an ST-segment. The data suggest that extreme abbreviation of the Jpoint-T peak interval may help distinguish patients with a SQTS from healthy subjects with an apparent abbreviation of the ST-segment and shortened QT intervals. ${ }^{6}$ Moreover, the Tpeak-Tend interval and the Tpeak-Tend/QT ratio, an ECG index of spatial dispersion of repolarisation, are significantly augmented in cases of SQTS.7 Measurement of T-wave alternans in SQTS, even if disappointing, does not imply that dynamic changes in QT interval or increased QT apex-QT end interval are useless. ${ }^{8}$ In the current case, we detected the dynamic T-wave changes 
Figure 1: Twelve-lead electrocardiogram showing a short QT interval and tall, peaked T-waves

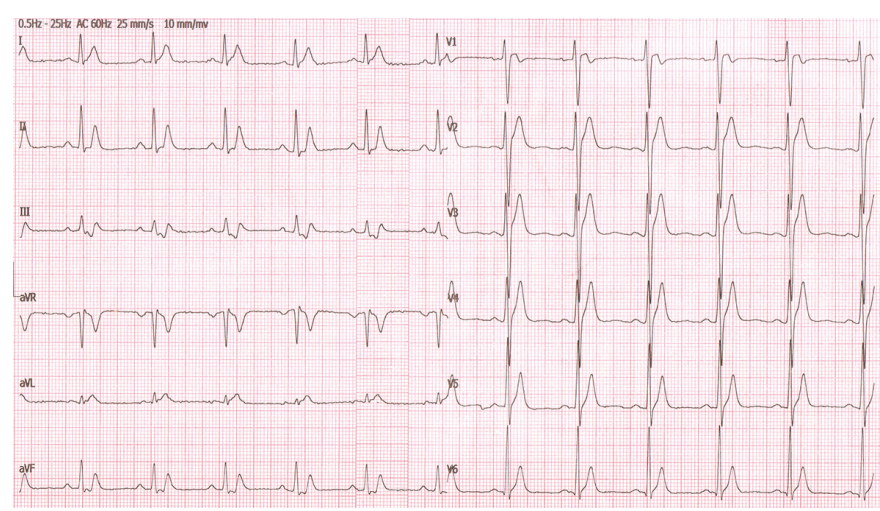

with a 'T-wave hump' appearance in the higher intercostal ECG recordings, and speculate that those changes may reflect underlying repolarisation abnormality. Indeed, the T-wave changes ('humps' or notches) that have been well described in long QT syndrome (LQTS) patients, ${ }^{9}, 10$ are a marker of increased arrhythmogenic risk and are not only restricted to patients with LQTS, but are also described in patients without LQTS. ${ }^{11}$
Figure 2: Precordial electrocardiograms taken at the 2, 3 and 4 intercostal spaces show dynamic T-wave changes (arrows) with T-wave hump appearance (arrow in B)

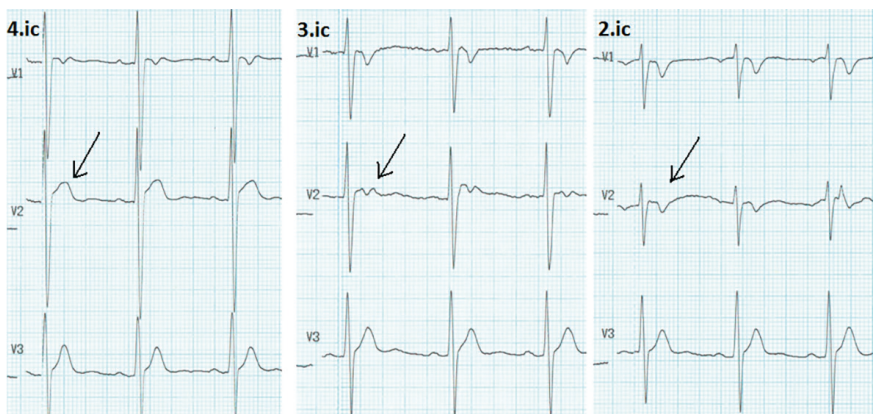

Therefore, these spatial changes by higher intercostal space recordings as a surrogate marker of underlying repolarisation abnormality may help in the diagnosis of SQTS in addition to the measurement of the duration of QT interval from the 12-lead ECG, ${ }^{12}$ and may be used as a clue for differentiation of SQTS patients from normal healthy individuals with a short QT interval. However, further research is necessary to prove if T-wave hump is indeed another clue for identifying SQTS patients.
1. Mazzanti A, Kanthan A, Monteforte N, et al., Novel insight into the natural history of short QT syndrome, I Am Coll Cardiol, 2014:63:1300-8

2. Gollob MH, Redpath CJ, Roberts JD, The short QT syndrome: proposed diagnostic criteria, J Am Coll Cardiol, 2011;57:802-12

3. Priori SG, Wilde AA, Horie M, et al., HRS/EHRA/APHRS expert consensus statement on the diagnosis and management of patients with inherited primary arrhythmia syndromes: document endorsed by HRS, EHRA, and APHRS in May 2013 and by ACCF, AHA, PACES, and AEPC in June 2013, Heart Rhythm, 2013;10:1932-63

4. Bjerregaard P, Proposed diagnostic criteria for short QT syndrome are badly founded, I Am Coll Cardiol,
2011;58:549-50; author reply 550-41

5. Gussak I, Brugada P, Brugada J, et al., Idiopathic short QT interval: a new clinical syndrome? Cardiology, 2000;94:99-102

6. Anttonen O, Junttila MJ, Maury $\mathrm{P}$, et al., Differences in twelve-lead electrocardiogram between symptomatic and asymptomatic subjects with short QT interval, Heart Rhythm, asymptomatic

7. Anttonen $O$, Vaananen $H$, Junttila J, et al., Electrocardiographic transmural dispersion of repolarization in patients with transmural dispersion of repolarization in patients with
inherited short QT syndrome, Ann Noninvasive Electrocardiol inherited short Q

8. Maury P, Extramiana F, Giustetto $C$, et al., Microvolt T-wave alternans in short QT syndrome, Pacing Clin Electrophysiol,
2012;35:1413-9.

9. Lehmann MH, Suzuki F, Fromm BS, et al., T wave "humps" as a potential electrocardiographic marker of the long QT syndrome J Am Coll Cardiol, 1994;24:746-54.

10. Sensoy $B$, Ozeke $O$, Canpolat $U$, et al. Postexercise recovery phase T-wave notching in concealed long QT syndrome, Herz, 2015:40:153-6.

11. Wedekind $H$, Schulze-Bahr E, Dionlagic $H$, Postextrasystolic "T wave hump" augmentation as a marker of increased arrhythmogenic risk in the long QT syndrome, Heart, 2002;88:633.

12. Anttonen $\mathrm{O}$, Junttila J, Giustetto $\mathrm{C}$, et al., T-Wave morphology in short QT syndrome, Ann Noninvasive Electrocardiol, 2009;14:262-7. 